\title{
Unemployment and suicide. Evidence for a causal association?
}

\author{
T A Blakely, S C D Collings, J Atkinson
}

J Epidemiol Community Health 2003;57:594-600

See end of article for authors' affiliations

.....................

Correspondence to: Dr T A Blakely, Department of Public Health, Wellington School of Medicine, University of Otago, PO Box 7343 Wellington, New Zealand; tblakely@wnmeds.ac.nz

Accepted for publication 12 February 2003 of labour force status and socioeconomic posiObjectives: To determine the
tion with death by suicide.

Design: Cohort study assembled by anonymous and probabilistic record linkage of census and mortality records.

Participants: 2.04 million respondents to the New Zealand 1991 census aged 18-64 years. Main outcome measure: Suicide in the three years after census night.

Results: The age adjusted odds ratios (95\% confidence intervals) of death by suicide among 25 to 64 year olds who were unemployed compared with employed were 2.46 (1.10 to 5.49$)$ for women and 2.63 ( 1.87 to 3.70 ) for men. Similarly increased odds ratios were observed for the non-active labour force compared with the employed. Strong age only adjusted associations of suicide death with the socioeconomic factors of education (men only), car access, and household income were observed. Compared with those who were married on census night, the non-married had odds ratios of suicide of 1.81 (1.22 to 2.69) for women and 2.08 (1.66 to 2.61) for men. In a multivariable model the association of socioeconomic factors with suicide reduced to the null. However, marital status and labour force status remained strong predictors of suicide death. Unemployment was also strongly associated with suicide death among 18-24 year old men. Sensitivity analyses suggested that confounding by mental illness might explain about half, but not all, of the association between unemployment and suicide.

Conclusions: Being unemployed was associated with a twofold to threefold increased relative risk of death by suicide, compared with being employed. About half of this association might be attributable to confounding by mental illness.
S uicide is associated with unemployment. ${ }^{1}$ Three explanations are possible ${ }^{2}$ : unemployment may confer vulnerability by increasing the impact of stressful life events; it may indirectly cause suicide by increasing the risk of factors that precipitate suicide (for example, mental illness, financial difficulties); or it may be a non-causal association because of confounding or selection by factors that predict both unemployment status and suicide risk.

Studies controlling for confounding by social factors find an approximately twofold excess suicide risk among the unemployed, ${ }^{45}$ but the possibility remains of health selection or residual confounding. Health selection is where poor health precedes and predicts both unemployment and death causing a spurious association of unemployment with suicide. Data from the British general household survey on the prevalence of limiting longstanding illness by labour force status were consistent with health selection into the non-active labour force (that is, excluding both the employed and unemployed), but not into the unemployed category (that is, actively seeking and available for work). ${ }^{6}$ Another test of health selection is that a weaker association of unemployment with poor health would be expected in times of high background unemployment rates, as a greater proportion of "ordinary" people (that is, not just people with poor health or other characteristics conferring vulnerability) are afflicted with unemployment. The evidence based on this test is mixed. Findings from the OPCS Longitudinal Study in the UK demonstrate a similarly strong association of unemployment with all cause mortality (and suicide) in times of both high (1981 census) and low unemployment (1971 census). ${ }^{7}$ However, Finnish research suggests the opposite with lower relative risks of suicide for the unemployed compared with employed in times of high unemployment rates. ${ }^{8}$ Beyond health selection, residual confounding by socioeconomic or other variables (for example, childhood circumstances and mental health) has been suggested as the reason for the observed association of unemployment with suicide. For example, a New Zealand casecontrol study of serious suicide attempts found an unadjusted odds ratio of 4.2 (95\% confidence intervals 2.6 to 6.8 ), reducing to 1.95 (0.95 to 4.0$)$ after control for current mental disorder and further reducing to 1.7 (0.8 to 3.5$)$ after additional control for childhood and family factors. ${ }^{3}$ As acknowledged by the authors this study does not rule out unemployment as a causal factor because mental disorders may actually be a pathway variable between unemployment and suicide (rather than just a confounder). Also the central estimates of the relative risks are greater than 1.7 and measured with imprecision (wide 95\% confidence intervals). A Danish record linkage case-control study found that 16-78 year olds in 1980-94 receiving the unemployment benefit for less than $20 \%$ and $20 \%$ to $100 \%$ of the last year, respectively, had relative risks of suicide of 1.10 (0.79 to 1.53 ) and 1.89 ( 1.50 to 2.38 ) compared with working adults. ${ }^{9}$ Controlling for socioeconomic factors and psychiatric hospitalisations reduced these relative risks to 0.93 (0.66 to 1.33 ) and 1.35 (1.03 to 1.76 ), respectively. However, comparable results unadjusted for psychiatric hospitalisations (both a possible pathway and confounding variable) were not presented in this Danish study. Perhaps the best evidence for a causal association comes from longitudinal studies that find unemployment predates symptoms of depression and anxiety. ${ }^{10}$ Another longitudinal study using methods to control for observed and unobserved confounding found that duration of unemployment among a cohort of young adults $(n=1053)$ was positively associated with suicidal ideation (reported by $22.9 \%$ of the cohort, $\mathrm{p}<0.005$ ) and marginally 


\section{What is already known}

Not being employed is known to be associated with death by suicide, but it is unclear whether this association is causal Lower socioeconomic position has also been associated with increased suicide risk, with some studies suggesting that this association is attributable to confounding by labour force status.

positively associated with suicidal attempts (reported by $6.3 \%$ of the cohort, $\mathrm{p}>0.40) .{ }^{11}$

The 1991 cohort of the New Zealand Census-Mortality Study (NZCMS) provides a useful opportunity to examine the relation between labour force status and socioeconomic factors with suicide. Firstly, unemployment in New Zealand peaked at $10.7 \%$ in 1991 , having risen steeply from $4.0 \%$ in 1987. ${ }^{12}$ Secondly, suicide rates in New Zealand during the early 1990s were high compared with other industrialised countries-particularly for youth suicide for which New Zealand and Finland had the highest rates. ${ }^{13}$ Thirdly, the New Zealand census collects information on a range of socioeconomic factors including income, permitting an assessment of financial pathways. Finally, the high rates of unemployment and suicide in 1991 and the fact that the NZCMS is a complete population study means that the statistical power is high.

\section{METHOD}

A cohort of 2.04 million 18-64 year olds was assembled by anonymous and probabilistic record linkage of New Zealand 1991 census records to mortality records. ${ }^{14}{ }^{15}$ Briefly, the matching variables in the record linkage were area of residence (neighbourhoods of approximate size 100 or 2000), sex, day, month, and year of birth, country of birth, and ethnicity. A coding error in one of the more important differentiating matching variables (for example, day of birth) or changing address between census night and death often meant no match was possible between the suicide record and the corresponding census record. Accordingly 699 of the 1194 $(59 \%)$ eligible suicide deaths aged 18 to 64 on census night occurring in the three years after census night were linked to a census record $(44 \%, 59 \%$, and $71 \%$ for $18-24,25-44$, and 45-64 year olds, respectively). Most of our analyses were conducted on the 25-64 year old adults given the poor linkage rates for 18 to 24 year olds because of high residential mobility. Data completeness and comparability for 15-17 year olds was insufficient to justify their inclusion. We did not include census respondents aged over 65 years because of the decreasing relevance of household income and labour force status after retirement.

The census variables used as independent variables in the cohort analyses of suicide risk were sex, age, ethnicity, marital status, labour force status, highest qualification, household income, and household car access. Marital status was based on a legal definition of marriage and categorised as currently married (married, remarried), compared with not married (never, separated, divorced). Labour force status was classified as the employed, unemployed (that is, actively seeking work and available for work) and non-active labour force (for example, retired, students, homemakers, permanently sick). Highest qualification included post-school qualifications for 25-64 year olds, but was limited to school qualifications for 18-24 year olds. Household income was adjusted for the number of people in each household. ${ }^{16}$

Age adjusted odds ratios of suicide death (ICD-9 codes 950-959 and 980-989) were calculated for all census respondents with complete data for each socioeconomic factor using logistic regression models run separately by sex and age group (18-24, 25-44, and 45-64 years). Of the 1654314 census respondents aged 25 to 64 years old, 1272015 (76.9\%) had complete data for all demographic and social variables and were used to calculate multivariable odds ratios. This restricted dataset included 429 of the 558 linked suicide deaths $(77 \%)$. Because of the short duration of follow up and suicide being a comparatively uncommon event the odds ratios are good approximations of the risk ratios.

\section{Sensitivity analyses Linkage bias}

It was possible that the record linkage success varied by socioeconomic status resulting in biased odds ratios. Extensive sensitivity analyses published elsewhere suggest that such linkage bias does not substantially affect cohort analyses so long as demographic factors are controlled..$^{14}{ }^{17}{ }^{18}$ However, for this paper we also conducted a specific sensitivity analysis exploring the possible impact of linkage bias. We used a New Zealand index of small area socioeconomic deprivation (NZDep91 ${ }^{19}$ ) that could be derived for most of the suicides (regardless of linkage status). The components of this index include the proportions at a small area level (involving about 100 individuals) of census variables such as individuals with/ in: no telephone access; no car access; receipt of a means tested benefit; unemployment; low household income; single parent families; nil qualifications; non-tenured homes; and household crowding. ${ }^{19} 20$ The index value was then assigned to suicide records using the address on the death registration form, allowing us to determine the age adjusted relative risk of linkage to a census record for suicides in the most deprived $50 \%$ of small areas compared with the least deprived 50\% using log-link regression.

\section{Excluding 60-64 year olds}

Census respondents aged 60-64 years of age may have already retired, causing them to be classified as non-active labour force status and (possibly) to have a lower household income than would have been the case during their working lives. Therefore, we excluded 60-64 year olds from some analyses to check for possible distortion by including this age group.

\section{Confounding by mental illness}

We investigated the possibility that the unemploymentsuicide association observed in our study was attributable to confounding by mental illness using basic sensitivity analysis methods. ${ }^{21}$ Three pieces of external information were required: the prevalence of mental illness in the community, the relative risk of mental illness in the unemployed compared with the employed, and the relative risk of suicide in those with mental illness compared with those without mental illness. Firstly, the six month prevalence of mental illness (affective disorder, substance use, schizophrenia and schizophreniform disorders) in New Zealand adults has been measured at $21.4 \%{ }^{22}$ Goldberg and Huxley (1992) estimate the annual prevalence of mental disorder in the UK at about 30\% in the community (level 1), 23\% in primary care (level 2) and at about $10 \%$ for mental disorders detected by doctors. ${ }^{23}$ Accordingly, we set our central estimate of the community prevalence of mental illness at $20 \%$, with a low and high estimate of $10 \%$ and $30 \%$. Secondly, among Australian young adults the risk of being a "case" of mental disorder according to General Health Questionnaire (GHQ) screening is about 1.5 times greater among the unemployed compared with the employed. ${ }^{24} \mathrm{New}$ Zealand data, although not presented as case rates, have showed comparable differences between adults who were not employed compared with employed using the GHQ. ${ }^{25}$ We set our central relative risk estimate at 1.5 , with a low and high estimate of 1.25 and 2.0. Thirdly, we set our central estimate of the relative risk of suicide for people with mental illness compared with people with no mental illness at $20 \quad($ low $=5$, high $=50$ ), consistent with New Zealand evidence. ${ }^{26}$ We used Microsoft Excel SR-2 to calculate the adjusted relative risk of 
Table 1 Age adjusted odds ratios (95\% confidence intervals) of suicide by marital status and socioeconomic factors among 1.65 million 25-64 year olds

\begin{tabular}{|c|c|c|c|c|c|c|}
\hline & \multicolumn{3}{|l|}{ Women } & \multicolumn{3}{|l|}{ Men } \\
\hline & Deaths & Number & OR $(95 \% \mathrm{Cl})$ & Deaths & Number & OR $(95 \% \mathrm{Cl})$ \\
\hline \multicolumn{7}{|l|}{$25-44$ years } \\
\hline \multicolumn{7}{|l|}{ Marital status } \\
\hline Married & 33 & 334032 & 1 & 117 & 303861 & 1 \\
\hline Not married & 36 & 187746 & $1.95(1.21,3.16)$ & 147 & 203112 & $1.93(1.49,2.48)$ \\
\hline \multicolumn{7}{|c|}{ Highest qualification } \\
\hline Tertiary & 21 & 126651 & $1.08(0.58,1.99)$ & 36 & 108255 & $0.52(0.35,0.77)$ \\
\hline Trade & 9 & 83733 & $0.78(0.36,1.71)$ & 81 & 144417 & $0.86(0.64,1.17)$ \\
\hline School & 21 & 150255 & $0.93(0.50,1.73)$ & 54 & 106836 & $0.78(0.56,1.09)$ \\
\hline Nil & 24 & 153249 & 1 & 90 & 139158 & 1 \\
\hline \multicolumn{7}{|c|}{ Labour force status } \\
\hline Employed & 33 & 318537 & 1 & 162 & 415785 & 1 \\
\hline Unemployed & 9 & 30801 & $2.42(1.06,5.49)$ & 36 & 38490 & $2.35(1.64,3.38)$ \\
\hline Non-active & 30 & 172434 & $1.87(1.13,3.10)$ & 63 & 52689 & $3.07(2.30,4.11)$ \\
\hline \multicolumn{7}{|c|}{ Household car access } \\
\hline Two or more & 33 & 253551 & 1 & 117 & 251805 & 1 \\
\hline One & 24 & 213294 & $0.98(0.58,1.65)$ & 105 & 198588 & $1.14(0.88,1.49)$ \\
\hline $\mathrm{Nil}$ & 9 & 35640 & $2.36(1.15,4.82)$ & 18 & 26916 & $1.59(0.99,2.55)$ \\
\hline \multicolumn{7}{|c|}{ Equivalised household income } \\
\hline$\geqslant \$ 50000$ & 15 & 103842 & $0.70(0.36,1.39)$ & 45 & 113574 & $0.48(0.33,0.70)$ \\
\hline$\$ 30-\$ 49999$ & 15 & 124080 & $0.59(0.30,1.17)$ & 60 & 129903 & $0.57(0.40,0.81)$ \\
\hline$\$ 20-\$ 29999$ & 9 & 86343 & $0.56(0.26,1.23)$ & 54 & 87873 & $0.73(0.51,1.05)$ \\
\hline$<\$ 20000$ & 21 & 114741 & 1 & 69 & 85323 & 1 \\
\hline \multicolumn{7}{|l|}{$45-64$ years } \\
\hline \multicolumn{7}{|l|}{ Marital status } \\
\hline Married & 42 & 223305 & 1 & 102 & 241248 & 1 \\
\hline Not Married & 21 & 88638 & $1.35(0.81,2.24)$ & 57 & 72375 & $1.88(1.36,2.60)$ \\
\hline \multicolumn{7}{|c|}{ Highest qualification } \\
\hline Tertiary & 12 & 59382 & $1.62(0.80,3.25)$ & 15 & 50679 & $0.64(0.37,1.12)$ \\
\hline Trade & 6 & 32493 & $1.59(0.67,3.77)$ & 48 & 85995 & $1.14(0.78,1.67)$ \\
\hline School & 21 & 64182 & $2.52(1.38,4.62)$ & 33 & 46920 & $1.35(0.88,2.09)$ \\
\hline $\mathrm{Nil}$ & 18 & 146745 & 1 & 60 & 122964 & 1 \\
\hline \multicolumn{7}{|c|}{ Labour force status } \\
\hline Employed & 21 & 156456 & 1 & 84 & 220134 & 1 \\
\hline Unemployed & 6 & 8193 & $0.90(0.12,6.67)$ & 12 & 13491 & $2.28(1.24,4.17)$ \\
\hline Non-active & 42 & 147288 & $2.54(1.45,4.45)$ & 60 & 79989 & $2.37(1.63,3.46)$ \\
\hline \multicolumn{7}{|c|}{ Household car access } \\
\hline Two or more & 24 & 155070 & 1 & 66 & 171768 & 1 \\
\hline One & 27 & 122928 & $1.47(0.85,2.56)$ & 69 & 109725 & $1.61(1.15,2.26)$ \\
\hline Nil & 6 & 20445 & $2.54(1.13,5.70)$ & 12 & 14673 & $1.75(0.90,3.40)$ \\
\hline \multicolumn{7}{|c|}{ Equivalised household income } \\
\hline$\geqslant \$ 50000$ & 12 & 66042 & $0.55(0.25,1.20)$ & 30 & 78165 & $0.47(0.29,0.75)$ \\
\hline$\$ 30-\$ 49999$ & 18 & 78783 & $0.79(0.40,1.53)$ & 42 & 83487 & $0.59(0.38,0.91)$ \\
\hline$\$ 20-\$ 29999$ & 12 & 54129 & $0.75(0.36,1.58)$ & 33 & 50313 & $0.77(0.49,1.22)$ \\
\hline$<\$ 20000$ & 21 & 71157 & 1 & 45 & 55863 & 1 \\
\hline
\end{tabular}

Raw numbers are random rounded to the nearest multiple of three as per Statistics New Zealand protocol with a minimum released value of 6 . However all regression analyses use exact counts. $100 \%$ of the cohort had a valid value for marital status, $98.0 \%$ for education, $100 \%$ for labour force status, $95.2 \%$ for car access, and $83.6 \%$ for equivalised household income.

suicide by unemployment for the $27(3 \times 3 \times 3)$ combinations of the input variables above.

\section{RESULTS}

\section{Age adjusted analyses}

Among 25-44 year old men and women and 45-64 year old men there was an approximately twofold to threefold excess risk of suicide among the unemployed compared with the employed (table 1). The odds ratios for unemployed 45-64 year old women (compared with employed) was 0.90 , but the $95 \%$ confidence interval was wide (0.12 to 6.67). For each of the groups stratified by sex and age in table 1 increased suicide risk was associated with decreased equivalised household income and access to only one or no cars in the household compared with two or more cars. There was a suggestion of increased suicide risk with lower educational qualifications among 25-44 year old men, but not older men. Among 18 to 24 year old men an increased risk of suicide was associated with lower school qualifications, lower household income, and unemployment (table 2 ). There were few suicides among 18 to
24 year old women, and no pattern of suicide by labour force status or socioeconomic factors was evident.

\section{Multivariable analyses}

The age only adjusted odds ratios for this restricted cohort (table 3) are similar to those for the full cohort (table 1), arguing against selection bias. Adjusting for other socioeconomic factors, compared with adjusting for age only, reduced the unemployed odds ratio for suicide from 2.46 ( 1.10 to 5.49 ) to 2.34 ( 1.01 to 5.42 ) for women and from 2.63 ( 1.87 to 3.70 ) to 2.26 ( 1.56 to 3.28 ) for men. In contrast with the persistent independent associations of labour force status and marital status with suicide, the associations of income, car access (men only) and highest qualification (men only) with suicide were essentially reduced to the null after control for other socioeconomic factors. These reductions were mainly attributable to controlling for labour force status. Finally, additional inclusion of small area deprivation (that is, NZDep91) in the multivariable analyses neither changed these findings nor demonstrated an independent association of small area deprivation with suicide (results available from the authors). 
Table 2 Age adjusted odds ratios (95\% confidence intervals) of suicide by education, labour force status, and household income among 18-24 year olds

\begin{tabular}{|c|c|c|c|c|c|c|}
\hline & \multicolumn{3}{|l|}{ Women } & \multicolumn{3}{|l|}{ Men } \\
\hline & Deaths & Number & OR $(95 \% \mathrm{Cl})$ & Deaths & Number & OR $(95 \% \mathrm{Cl})$ \\
\hline \multicolumn{7}{|c|}{ Highest school qualification } \\
\hline Year 11-12 & 15 & 95034 & $0.93(0.37,2.35)$ & 39 & 86715 & $0.53(0.34,0.80)$ \\
\hline Year 10 & 6 & 45327 & $0.73(0.23,2.30)$ & 27 & 44688 & $0.75(0.47,1.20)$ \\
\hline $\mathrm{Nil}$ & 9 & 45855 & 1 & 48 & 57627 & 1 \\
\hline \multicolumn{7}{|c|}{ Labour force status } \\
\hline Employed & 12 & 104700 & 1 & 57 & 121401 & 1 \\
\hline Unemployed & 6 & 24879 & $1.02(0.29,3.59)$ & 36 & 29871 & $2.51(1.65,3.84)$ \\
\hline Non-active & 12 & 64134 & $1.29(0.56,2.94)$ & 27 & 44913 & $1.30(0.82,2.06)$ \\
\hline \multicolumn{7}{|c|}{ Equivalised household income } \\
\hline$\geqslant \$ 50000$ & 6 & 38268 & $0.65(0.18,2.29)$ & 15 & 42705 & $0.49(0.25,0.98)$ \\
\hline \$30-\$49999 & 6 & 48090 & $0.91(0.31,2.71)$ & 36 & 50445 & $1.04(0.59,1.81)$ \\
\hline$\$ 20-\$ 29999$ & 6 & 30108 & $1.06(0.32,3.47)$ & 21 & 30834 & $1.01(0.54,1.88)$ \\
\hline$<\$ 20000$ & 6 & 37638 & 1 & 18 & 28233 & 1 \\
\hline
\end{tabular}

Raw numbers are random rounded to the nearest multiple of three as per Statistics New Zealand protocol with a minimum released value of 6 . However all regression analyses use exact counts. Of the 18-24 year olds ( $n=389898), 96.2 \%$ had a valid value for education and $78.6 \%$ for equivalised household income.

Table 3 Age only and multivariable adjusted odds ratios (95\% confidence intervals) of suicide among 1.27 million 25-64 year olds with complete data

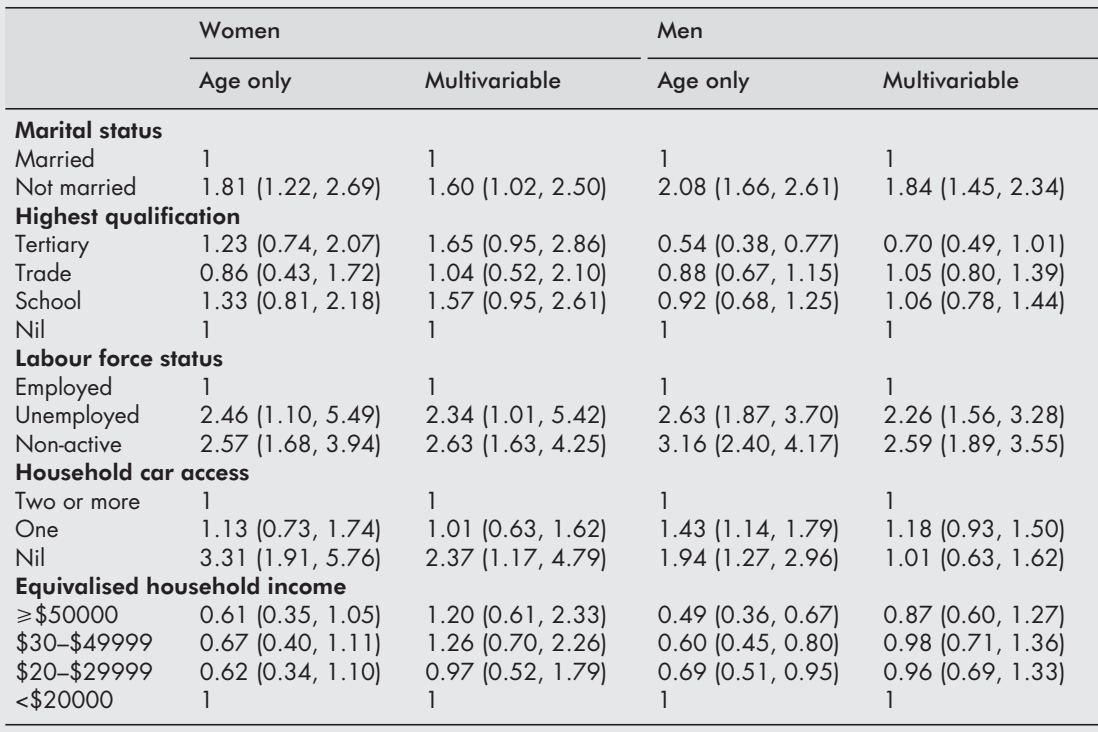

Raw numbers are random rounded to the nearest multiple of three as per Statistics New Zealand protocol with a minimum released value of 6 . However all regression analyses use exact counts. Multivariable logistic regression models control for variables as shown in the table, five year age group, ethnicity (Maori, non-Maori) and household tenure (owner occupied, private tenancy, and public tenancy).

Among 18 to 24 year old men with complete data for labour force status, highest school qualification, car access and household income (81 suicides including 21 among the unemployed), the age only adjusted odds ratio for the unemployed was 2.12 ( 1.29 to 3.50 ) reducing to 1.85 ( 1.09 to 3.16 ) after multivariable control.

\section{Sensitivity analysis-linkage bias}

The percentage of suicide deaths linked varied from $44 \%$ for 18 to 24 year old men to $74 \%$ for $45-64$ year old women (table 4 ). However, within age by sex strata 25-64 year old suicide deaths among people living in the most deprived areas were only $7 \%$ less likely to be linked than suicide deaths in the least deprived small areas (RR 0.93, 95\% CI 0.84 to 1.02; table 4).

\section{Sensitivity analysis-excluding 60-64 year olds}

Excluding 60-64 year olds had little impact on the results (full results available from authors). For example, the age adjusted

\section{Key points}

- Not being employed is known to be associated with death by suicide, but it is unclear whether this association is causal.

- Lower socioeconomic position has also been associated with increased suicide risk, with some studies suggesting that this association is attributable to confounding by labour force status.

- This study of the New Zealand adult population finds that not being employed is strongly associated with suicide.

- This association is not attributable to confounding by socioeconomic position and is unlikely to be due either to health selection or confounding by mental illness.

- There is little suggestion of an independent association of socioeconomic position with suicide death after controlling for labour force status. 
Table 4 Suicides in 1991-94 linked to a 1991 census record, and the relative risk (95\% confidence intervals) of being linked for suicides from the most socioeconomically deprived $50 \%$ of small areas compared with the least deprived $50 \%$

\begin{tabular}{lll}
\hline & $\begin{array}{l}\text { Fraction of suicide deaths } \\
\text { linked to census record (\%) }\end{array}$ & $\begin{array}{l}\text { RR of linkage for most } \\
\text { compared to least deprived* }\end{array}$ \\
\hline $\mathbf{1 8 - 2 4}$ year olds & $27 / 51(53)$ & $1.32(0.67,2.59)$ \\
Women & $120 / 273(44)$ & $1.13(0.82,1.54)$ \\
Men & $69 / 111(62)$ & $0.83(0.64,1.06)$ \\
$\mathbf{2 5 - 4 4}$ year olds & $261 / 450(58)$ & $0.97(0.82,1.13)$ \\
Women & $69 / 93(74)$ & $1.15(0.90,1.48)$ \\
Men & $159 / 222(72)$ & $0.85(0.72,1.00)$ \\
$\mathbf{4 5 - 6 4}$ year olds & Women & $0.93(0.84,1.02)$ \\
Men & $555 / 873(64)$ & \\
$\mathbf{2 5 - 6 4}$ years combined (both sexes) &
\end{tabular}

Raw numbers are random rounded to the nearest multiple of three as per Statistics New Zealand protoco with a minimum released value of 6 . However, all regression analyses use exact counts. ${ }^{*}$ The relative risk is calculated by a log-link regression of the probability of a suicide being linked, controlling for age. The analyses include 1037 of the total 1197 suicides (86.6\%) with a valid value for small area deprivation.

\section{What this paper adds}

This study of the entire New Zealand adult population finds that not being employed is strongly associated with suicide, that this association is not due to confounding by socioeconomic status, and is probably not due to either health selection or confounding by mental illness. Conversely, there is little suggestion of an independent association of socioeconomic status with suicide death after controlling for labour force status.

odds ratio of 0.55 (0.47) for high household income men (women) in table 1 became 0.51 (0.47) after excluding 60-64 year olds, and the odds ratio of 2.28 (0.90) for unemployed men (women) became 2.44 (0.91). The multivariable odds ratio for unemployed compared with employed men (women) was 2.47 (2.01) for 25-59 year olds compared with 2.26 (2.34) for 25-64 year olds shown in table 3.

\section{Sensitivity analysis-confounding by mental illness}

Using crude 25-64 year old male data (table 1) the risk of suicide for the unemployed was 0.00084 (33/39 312) and for the employed was 0.00032 (168/519 195), giving a relative risk of 2.59. (The analogous multivariable relative risk shown in table 3 was 2.26.) Using the crude data and the parameters described in the Methods section, our "best estimate" of the relative risk of suicide for the unemployed controlling for mental illness was 1.88 (a $47 \%$ reduction in excess relative risk), with a range of 1.35 to 2.43 (table 5 ).

\section{DISCUSSION}

We found a strong association between being unemployed (and in the non-active labour force) with suicide for male and female adults (table 1). The unemployment association was comparatively unaffected after controlling for income, education, car access, deprivation, and marital status (table 3 ). In stark contrast, analyses in the NZCMS by sex for 25-64 year olds for other causes of death (cancer, cardiovascular disease, and unintentional injury) demonstrated only a modest univariate association with unemployment (odds ratios ranging from 0.62 to 1.42 ) that reduced after control for socioeconomic factors (range 0.48 to 1.20 ). ${ }^{15}$ A similar pattern was evident among young New Zealand men (table 2), who have one of the highest suicide rates in the developed world. ${ }^{13}$ This pattern does not support the association of unemployment with suicide being attributable to confounding (or mediation) by other social factors.
Incomplete record linkage in the NZCMS of eligible mortality records to census records because of coding errors (on either census or mortality files) and residential mobility between census night and time of suicide death may result in linkage bias. This linkage bias may play out as a differential misclassification bias of the mortality outcome in the cohort analyses. This potential bias is of particular concern for 18 to 24 year olds where suicide linkage rates were low due to residential mobility. However, among 25-64 year olds the linkage rates are greater and extensive sensitivity analyses published elsewhere suggest little impact of linkage bias on cohort analyses after adjusting for age group and ethnicity. ${ }^{14} 1718$ Results in table 4 of this paper show that 25 to 64 year old suicide deaths from more deprived neighbourhoods were $7 \%$ less likely to be linked to a census record than suicide deaths from less deprived neighbourhoods. Assuming a similar modest linkage bias exists for other socioeconomic factors that we were unable to measure on mortality data, then we will have underestimated the strength of association of, say, low income with suicide. We would also expect that unemployed people who commit suicide would have lower linkage rates than employed people who commit suicide due to greater residential mobility between census night and death among unemployed people. Therefore, our associations of unemployment with suicide are probably also underestimated.

Our data did not allow us to directly control for other potential confounding factors such as family circumstances and mental illness. However, our adjustments for adult socioeconomic factors that should be correlated with early social exposures (including education-a marker of social conditions in childhood) did not change the unemployment-suicide association. Mental illness may be a confounder of the unemployment-suicide association by directly causing one to become unemployed (that is, health selection that may occur with only three years of follow up in our study) or attributable to being associated with both unemployment and suicide for reasons other than health selection. Such confounding or health selection may partly account for the increased risk among the non-active labour force, but this is less likely to be so for the unemployed for several reasons. Firstly, most people not working because of poor health would be classified in the non-active labour force (rather than as unemployed) ${ }^{6}$ as they would neither be actively looking nor available for work. Secondly, among the unemployed in this cohort the all cause mortality increased during the three year follow up, the reverse of what would be expected with health selection. ${ }^{15}$ Thirdly, the high unemployment rate in 1991 should militate against health selection. ${ }^{78}$ 
Table 5 Sensitivity analysis estimates of the relative risk of suicide among the unemployed compared with the employed controlling for mental illness, using the crude relative risk estimate of 2.59 for 25-64 year old men as the starting point

\begin{tabular}{|c|c|c|c|c|c|c|c|c|c|}
\hline \multirow{2}{*}{$\begin{array}{l}\text { Prevalence of mental illness } \\
\text { in the total population }\end{array}$} & \multicolumn{3}{|l|}{$10 \%$} & \multicolumn{3}{|l|}{$20 \%$} & \multicolumn{3}{|l|}{$30 \%$} \\
\hline & 5 & 20 & 50 & 5 & 20 & 50 & 5 & 20 & 50 \\
\hline $\begin{array}{l}\text { RR of mental illness for } \\
\text { unemployed compared with } \\
\text { employed }=1.25\end{array}$ & 2.43 & 2.24 & 2.15 & 2.35 & 2.17 & 2.12 & 2.29 & 2.14 & 1.96 \\
\hline $\begin{array}{l}\text { RR of mental illness for } \\
\text { unemployed compared with } \\
\text { employed }=1.5\end{array}$ & 2.13 & 1.98 & 1.85 & 2.16 & 1.88 & 1.79 & 2.07 & 1.83 & 1.77 \\
\hline $\begin{array}{l}\text { RR of mental illness for } \\
\text { unemployed compared with } \\
\text { employed }=2.0\end{array}$ & 1.85 & 1.64 & 1.45 & 1.89 & 1.49 & 1.38 & 1.76 & 1.43 & 1.35 \\
\hline
\end{tabular}

$R R$, relative risk. Modelling was based on the cohort of 25-64 year old men with complete data (that is, those represented in table 3). Of this cohort, 519195 were employed (168 suicide deaths during follow up), 39312 were unemployed (33), and 90243 were not in the labour force (84).

Fourthly, using the adult male crude relative risk of 2.59 among those men with complete data as a starting point (that is, those represented in table 3), our central estimate of what the relative risk might have reduced to after control for mental illness was 1.88 (table 5). For all possible combinations of the external parameter values in this sensitivity analysis the estimated relative risk never reached the null. It is possible that if our sensitivity analysis had also modelled the potential confounders for which we had data (for example, education) and the potential confounders for which we did not have data (for example, childhood and family factors), we might have found no residual association of unemployment with suicide. However, we think this possibility is unlikely for three reasons. Firstly, our multivariable analyses (table 3 ) did not demonstrate a large reduction in the relative risk of suicide after controlling for a range of socioeconomic factors. Correspondingly, we do not believe that the marginal effect of further adjustment for these socioeconomic factors (if possible) would substantially change the conclusions of our sensitivity analyses. Secondly, a case-control study of serious suicide attempts that adjusts for mental illness found little further reduction in the relative risk when additionally controlling for childhood and family factors. ${ }^{3}$ Furthermore, as some of the observed increased prevalence of mental illness among the unemployed will be attributable to becoming unemployed, ${ }^{10}{ }^{11}$ our sensitivity analysis adjustments for mental illness tend to overcontrol for confounding by mental illness. Finally, possible linkage bias described above would suggest that (if anything) we underestimated the crude association of unemployment with suicide that was used as the starting point for the sensitivity analyses shown in table 5 .

Any causal association between unemployment and suicide does not seem to be mediated by financial stress as the association reduced little after controlling for income (table 3). Other possible causal mechanisms linking unemployment and suicide include increased vulnerability to stressful life events or an increased risk of events or states that may precipitate suicidal behaviour (for example, substance use or mental illness). ${ }^{23}$ These mechanisms also suggest that any causal association between unemployment and suicide may be most apparent in the short-term. ${ }^{27}$ Consistent with this short lag-time, deteriorating mental health among the unemployed has been found for recent unemployment only ${ }^{10}$ and in a US study the independent association of unemployment with male suicide disappeared after two years of follow up. ${ }^{5}$

As with other studies ${ }^{3}$ the proportion of suicides attributable to unemployment among 25-64 year olds was comparatively small $(6 \%)$. It is important not to lose sight of the fact that other factors such as mental illness account for about half of suicide deaths. However, it is also important that the effect of unemployment is not discounted solely on this basis. Mismeasurement error of unemployment will underestimate the association of unemployment and suicide, and hence the population attributable risk. Also labour market characteristics considered more broadly have effects on mental health. Insecure employment has a deleterious effect on mental health, ${ }^{28}$ and among employed men in the 1991 NZCMS cohort those employed part time had a relative risk of suicide of 2.20 (95\% confidence interval 1.33 to 3.64) compared with the full time employed. ${ }^{15}$ Presumably, the causal mechanisms that underlie the unemployment-suicide association overlap with those underlying some of the excess risk of suicide among those not in the active labour force or full time employment and those who are not married.

A sociological interpretation might be that the unemployment rate in a society is a marker of a lack of social cohesion that in turn is associated with suicide. ${ }^{29}{ }^{30}$ Interestingly, an ecological study in the UK found that most causes of death were correlated with a small area measure of socioeconomic and material deprivation, but suicide (and cirrhosis) deaths were correlated with a small area measure of social fragmentation. ${ }^{31}{ }^{32}$ It is thus interesting to note that in our study the association of labour force status with suicide was not notably changed after control for a range of personal socioeconomic factors and a measure of small area measure of deprivation. Future priorities in the study of suicide and unemployment will be to conduct multilevel analyses of the association of area based measures of social fragmentation controlling for individual level unemployment and socioeconomic status, and to develop longitudinal measures of labour force status.

\section{ACKNOWLEDGEMENTS}

The NZCMS is conducted in collaboration with Statistics New Zealand and within the confines of the Statistics Act 1975. The NZCMS is primarily funded by the Health Research Council of New Zealand, with co-funding from the Ministry of Health. Comments on drafts of this paper were received from Annette Beautrais, Pete Ellis, David Fergusson, Ichiro Kawachi, Neil Pearce, Stephen Rosenman, Kate Scott, George Slim, and Alistair Woodward. We thank staff of Statistics New Zealand for assistance preparing the data necessary for this paper.

\section{Contributors}

Tony Blakely is the principal investigator of the NZCMS and is the guarantor of this study. Sunny Collings contributed to the design, analysis, interpretation, and drafting of the paper. June Atkinson conducted the majority of analyses, and contributed to the interpretation of results and revision of the paper. 


\section{Summary statistics New Zealand security statement}

(The full security statement is published at http:/ www.wnmeds.ac.nz/nzcms-info.html). The New Zealand Census Mortality Study (NZCMS) is a study of the relation between socioeconomic factors and mortality in New Zealand, based on the integration of anonymised population census data from Statistics New Zealand and mortality data from the New Zealand Health Information Service. The project was approved by Statistics New Zealand as a Data Laboratory project under the Microdata Access Protocols in 1997. The datasets created by the integration process are covered by the Statistics Act and can be used for statistical purposes only. Only approved researchers who have signed Statistics New Zealand's declaration of secrecy can access the integrated data in the Data Laboratory. For further information about confidentiality matters in regard to this study please contact Statistics New Zealand.

\section{Authors' affiliations}

T A Blakely, J Atkinson, Department of Public Health, Wellington School of Medicine, University of Otago, Wellington, New Zealand S C D Collings, Department of Psychological Medicine, Wellington School of Medicine, University of Otago

Funding: The New Zealand Census-Mortality Study (NZCMS) is principally funded by the Health Research Council of New Zealand, with co-funding from the Ministry of Health.

Conflicts of interests: none declared.

\section{REFERENCES}

1 Platt S, Hawton K. Suicidal behaviour and the labour market. In: Hawton $\mathrm{K}$, van Heeringen $\mathrm{K}$, eds. The international handbook of suicide and attempted suicide. New York: Wiley, 2000:310-84.

2 Jones S, Forster D, Hassanyeh F. The role of unemployment in parasuicide. Psychol Med 1991;21:169-76.

3 Beautrais A, Joyce P, Mulder R. Unemployment and serious suicide attempts. Psychol Med 1998;28:209-18.

4 Lewis G. Sloggett A. Suicide, deprivation, and unemployment: record linkage study. BM 1998;317:1283-6.

5 Kposowa A. Unemployment and suicide: a cohort analysis of socia factors predicting suicide in the US National Mortality Study. Psychol Med 2001;31:127-38.

6 Bartley M, Owen C. Relation between socioeconomic status, employment, and heath during economic change, 1973-93. BM 1996;313:445-9.

7 Moser K, Goldblatt P, Fox A, et al. Unemployment and mortality: comparison of the 1971 and 1981 longitudinal study census samples. BMU 1987:294:86-90.

8 Martikainen P, Valkonen T. Excess mortality of unemployed men and women during a period of rapidly increasing unemployment. Lancet 1996;348:909-12.

9 Mortensen $\mathbf{P}$, Agerbo E, Erikson T, et al. Pschiatric illness and risk factors for suicide in Denmark. Lancet 2000;355:9-12.

10 Montgomery S, Cook D, Bartley M, et al. Unemployment pre-dates symptoms of depression and anxiety resulting in medical consultation in young men. Int J Epidemiol 1999;28:95-100.
11 Fergusson D, Horwood L, Woodward L. Unemployment and psychosocial adjustment in young adults: causation or selection? Soc Sci Med 2001;53:305-20

12 Ministry of Social Policy. The social report: indicators of social well-being in New Zealand. Wellington: Ministry of Social Policy, 2001.

13 Ministry of Youth Affairs, Ministry of Health, Ministry of Maori Development. In our hands: New Zealand youth suicide prevention strategy. Wellington: Ministry of Youth Affairs, Ministry of Health, Ministry of Maori Development, 1998.

14 Blakely T, Salmond C, Woodward A. Anonymous linkage of New Zealand mortality and Census data. Aust NZ J Public Health 2000;24:92-5

15 Blakely T. Socio-economic factors and mortality among 25-64 year olds: The New Zealand census-mortality study. [Doctorate]. Otago: University of Otago, 2001. (Also at http://www.wnmeds.ac.nz/ nzcms-info. html)

16 Jensen J. Income equivalences and the estimation of family expenditure on children. Wellington: Department of Social Welfare, 1988.

17 Blakely T, Salmond C, Woodward A. Anonymous record linkage of 1991 census records and 1991-94 mortality records: The New Zealand Census-Mortality Study. Wellington: Department of Public Health, Wellington School of Medicine, University of Otago, 1999. (Also at http://www.wnmeds.ac.nz/nzcms-info.html)

18 Fawcett J, Blakely T, Atkinson J. Weighting the 81, 86, 91 \& 96 census-mortality cohorts to adjust for linkage bias. NZCMS technical report no 5. Wellington: Department of Public Health, Wellington School of Medicine and Health Sciences, University of Otago, 2002:92. (Also at http://www.wnmeds.ac.nz/nzcms-info.htmll.

19 Salmond C, Crampton P, Sutton F. NZDep91: A New Zealand index of deprivation. Aust NZ J Public Health 1998;22:835-7.

20 Salmond C, Crampton P. NZDep96-what does it measure? Social Policy Journal of New Zealand 2001;17:82-100.

21 Greenland S. Basic methods for sensitivity analysis and externa adjustment. In: Greenland S, Rothman K, eds. Modern epidemiology. 2nd edn. Philadelphia: Lippincott-Raven, 1998:343-58.

22 Oakley-Browne M, Joyce P, Wells E, et al. Christchurch psychiatric epidemiological study, part II: Six month and other period prevalences of specific psychiatric disorders. Aust NZ J Psychiatry 1989;23:327-40.

23 Goldberg D, Huxley P. Common mental disorders: a bio-social model. London: Routledge, 1992.

24 Morrell S, Taylor R, Quine S, et al. A cohort study of unemployment as a cause of psychological disturbance in Australian youth. Soc Sci Med 1999;38:1553-64.

25 Thornley C, Walton V, Romans-Clarkson S. Screening for psychiatric morbidity in men and women. NZ Med J 1991;104:505-7.

26 Beautrais A. Suicides and serious suicide attempts: two populations or one? Psychol Med 2001:31:837-45.

27 Makinen I. Effect on suicide rate of having reduced unemployment is uncertain. BM 1999;318:941

28 Ferrie J, Martikainen P, Shipley M, et al. Employment status and health after privatisation in white civil servants: prospective cohort study. $B M$ 2001;322:1-7.

29 Durkheim E. Suicide. Glencoe, IL: Free Press, 1951. (Original work published in 1898)

30 Kawachi I, Berkman L. Social cohesion, social capital, and health. In Berkman L, Kawachi I, eds. Social epidemiology. New York: Oxford University Press, 2000: 174-90.

31 Davey Smith G, Whitley E, Dorling D, et al. Area based measures of social and economic circumstances: cause specific mortality patterns depend on the choice of index. J Epidemiol Community Health 2001:55: 149-50.

32 Whitley E, Gunnell D, Dorling D, et al. Ecological study of social ragmentation, poverty, and suicide. BM 1999:319:1034-7. 